\title{
Early changes in biochemical markers of bone turnover and their relationship with bone mineral density changes after 24 months of treatment with teriparatide
}

\author{
A. Blumsohn • F. Marin • T. Nickelsen • K. Brixen • \\ G. Sigurdsson • J. González de la Vera • S. Boonen • \\ S. Liu-Léage • C. Barker • R. Eastell • \\ EUROFORS Study Group
}

Received: 29 April 2010 / Accepted: 16 August 2010/Published online: 12 October 2010

(C) The Author(s) 2010. This article is published with open access at Springerlink.com

\author{
Abstract \\ Meeting of The American Society for Bone and Mineral Research, \\ September 23rd-27th, 2005, Nashville, Tennessee, USA \\ A. Blumsohn $(\bowtie)$ \\ Department of Clinical Biochemistry, \\ Sheffield Teaching Hospitals NHS Foundation Trust, \\ Sheffield, UK \\ e-mail: ablumsohn@googlemail.com \\ F. Marin · T. Nickelsen $\cdot$ S. Liu-Léage $\cdot$ C. Barker \\ Lilly Research Center, \\ Windlesham, UK \\ K. Brixen \\ Department of Endocrinology, Universitethospital, \\ Odense, Denmark \\ G. Sigurdsson \\ Landspitalinn University Hospital, \\ Reykjavik, Iceland \\ J. González de la Vera \\ Department of Rheumatology, \\ Hospital Universitario Virgen Macarena, \\ Sevilla, Spain

\section{S. Boonen} \\ Leuven University Division of Geriatric Medicine, \\ Leuven, Belgium \\ R. Eastell \\ University of Sheffield, \\ Sheffield, UK
}

Summary We report the changes in biochemical markers of bone formation during the first 6 months of teriparatide therapy in postmenopausal women with osteoporosis according to previous antiresorptive treatment. Prior therapy

The EUROFORS Principal Investigators are listed in the Appendix.

Preliminary results of this study were presented at the 27th Annual does not adversely affect the response to teriparatide treatment. Similar bone markers levels are reached after 6 months of treatment.

Introduction The response of biochemical markers of bone turnover with teriparatide therapy in subjects who have previously received osteoporosis drugs is not fully elucidated. We examined biochemical markers of bone formation in women with osteoporosis treated with teriparatide and determined: (1) whether the response is associated with prior osteoporosis therapy, (2) which marker shows the best performance for detecting a response to therapy, and (3) the correlations between early changes in bone markers and subsequent bone mineral density (BMD) changes after 24 months of teriparatide.

Methods We conducted a prospective, open-label, 24-month study at 95 centers in 10 countries in 758 postmenopausal women with established osteoporosis ( $\mathrm{n}=181$ treatment-naïve) who had at least one post-baseline bone marker determination. Teriparatide ( $20 \mu \mathrm{g} / \mathrm{day})$ was administered for up to 24 months. We measured procollagen type I N-terminal propeptide (PINP), bone-specific alkaline phosphatase (b-ALP), and total alkaline phosphatase (t-ALP) at baseline, 1 and 6 months, and change in BMD at the lumbar spine, total hip and femoral neck from baseline to 24 months.

Results Significant increases in formation markers occurred after 1 month of teriparatide regardless of prior osteoporosis therapy. The absolute increase at 1 month was lower in previously treated versus treatment-naïve patients, but after 6 months all groups reached similar levels. PINP showed the best signal-to-noise ratio. Baseline PINP correlated positively and significantly with BMD response at 24 months.

Conclusions This study suggests that the long-term responsiveness of bone formation markers to teriparatide is not 
affected in subjects previously treated with antiresorptive drugs.

Keywords BMD · Bone markers · Bone turnover . Osteoporosis $\cdot$ Postmenopausal women $\cdot$ Teriparatide

\section{Introduction}

Teriparatide (recombinant human parathyroid hormone, rhPTH [1-34]) is a bone anabolic agent for the treatment of osteoporosis. Teriparatide induces new bone formation and increases trabecular connectivity as well as cortical bone thickness [1-4]. This results in favorable changes in bone strength at the spine [5] and cortical bone assessed at the distal radius [6] and proximal femur, both in primates and humans $[7,8]$. Treatment with teriparatide for 18 months reduces the risk of vertebral and nonvertebral fractures in postmenopausal women with osteoporosis as shown in the Fracture Prevention Trial [9], and shows superior BMD and fracture efficacy results compared with alendronate in subjects with glucocorticoid-induced osteoporosis [10].

Monitoring of changes in biochemical markers of bone turnover induced by bone active drugs plays an important role in characterizing drug effects on the basic multicellular units, and bone marker changes can be seen earlier than changes in BMD. Teriparatide treatment in patients with osteoporosis results in increases in markers of both bone formation and bone resorption, although the increase in bone formation markers derived from bone matrix proteins, such as type I procollagen terminal extensions and osteocalcin, occurs earlier and is larger than the increase in bone resorption markers [11, 12]. Data from a subset of osteoporosis treatment-naïve women in the Fracture Prevention Trial showed that early increases in bone formation markers had modest correlations with the BMD response to teriparatide [13] and with improvements in bone structure [14].

Currently, teriparatide is often used as a second-line treatment for patients with severe osteoporosis who have already received other osteoporosis therapies. Therefore, many patients receiving teriparatide have previously been treated with antiresorptive agents that may affect the bone marker response to teriparatide. Several clinical studies have shown that previous or concurrent treatment with alendronate reduces the bone marker and BMD response to teriparatide or full-length PTH(1-84) [15-17]. However, not all studies in patients previously treated with osteoporosis medications have shown this [18, 19], and direct comparisons of the bone marker response to teriparatide therapy in patients with and without prior antiresorptive therapy have not been performed. Moreover, although there are numerous biochemical markers of bone formation and bone resorption, they exhibit significant within-subject and between-subject variability [20], and it remains unclear which is the best bone marker for measuring the response to teriparatide therapy.

The European Study of Forsteo (EUROFORS) was a 2year, prospective, randomized trial which enrolled 868 postmenopausal women with established osteoporosis and was designed to investigate various sequential treatments of teriparatide. During the first year, all patients received teriparatide treatment, which was continued for 24 months in a subgroup of 503 patients [21]. Of the remaining patients who continued in the second year of the study, 100 were randomized to raloxifene treatment and 102 to no active antiresorptive treatment [22]. The dual-energy $x$-ray absorptiometry (DXA) and quantitative computerized tomography BMD and safety results of the patients who received teriparatide for 24 months have been published previously [21, 23, 24].

The objectives of the present planned analysis of EUROFORS were: (i) to compare the bone marker response during the first 6 months of teriparatide therapy in three distinct, predefined subgroups of patients with respect to prior antiresorptive treatment; (ii) to examine the responses of three biochemical markers of bone formation to teriparatide therapy and to determine which marker can most reliably detect a response to this therapy; and (iii) to determine whether early changes in bone markers are predictive of subsequent BMD changes.

\section{Subjects and methods}

\section{Study design}

EUROFORS was a multinational, multicenter, prospective, controlled, randomized, open-label, 2 year clinical trial in postmenopausal women with severe osteoporosis. Its primary objective was to compare the effects of three sequential treatments of teriparatide. The study was conducted at 95 centers in 10 European countries (Austria, Belgium, Denmark, France, Germany, Greece, Iceland, Portugal, Spain and United Kingdom), and consisted of two substudies and two treatment phases, which have been described in detail elsewhere [21, 22] and are summarized only briefly below.

Following a 1-month screening period, during which the patients' eligibility for enrolment was determined, all participants $(n=868)$ received once-daily subcutaneous selfinjections of teriparatide $(20 \mu \mathrm{g} /$ day $)$ together with supplements of calcium $(500 \mathrm{mg} /$ day) and vitamin D (400-800 IU/ day) throughout the first year of treatment (treatment phase 1). At 12 months post-baseline, patients entered treatment phase 2 and were either randomized to teriparatide $(n=305)$, 
raloxifene $(n=100)$ or no active antiresorptive treatment $(n=$ 102) for 12 months (substudy 1), or continued open-label teriparatide without randomization $(n=199)$ for 12 months (substudy 2) [21, 22].

The study was approved by ethical review boards at each clinical center, and all subjects provided written informed consent before participating in the study. All study methods and procedures were conducted in accordance with the ethical standards of the Declaration of Helsinki.

\section{Participants}

Ambulatory women (aged $\geq 55$ years) who were at least 2 years postmenopausal were enrolled if they had a T-score of -2.5 or less for BMD at the lumbar spine, total hip or femoral neck, and at least one documented vertebral or nonvertebral fragility fracture in the past 3 years. Eligible women also had to have baseline levels of serum parathyroid hormone, alkaline phosphatase and calcium within the reference ranges of the local laboratory where the sample was measured, and had to be free of severe or chronically disabling conditions other than osteoporosis. At least two of the lumbar vertebrae from L2 to L4 had to be evaluable for BMD.

Women were excluded if they were taking drugs or had diseases known to cause secondary forms of osteoporosis, or had contraindications to treatment with teriparatide or raloxifene, as described previously [21, 22].

Prior use of any antiresorptive (AR) drugs (including bisphosphonates, raloxifene, estrogens and estrogen/progestin therapy, calcitonin and vitamin D metabolites) was allowed without restrictions or washout periods, but these drugs had to be discontinued at baseline. Details of each subject's medical history and previous medication use were recorded, including dosages, start and stop dates of previous antiresorptive agents, dates, scanner types and results of historic BMD assessments, and a precise fracture history. Historic BMD results of the total hip obtained on Hologic, Lunar and Norland scanners were converted to standardized values, and historic BMD results of the lumbar spine and femoral neck obtained on Lunar and Norland scanners were converted to Hologic values using published and validated formulae [25, 26]. Based on these data, participating women were divided into three subgroups: (i) treatment-naïve; (ii) AR pretreated, and (iii) inadequate AR responders. Treatment-naïve patients had not received any anti-osteoporosis medications before entering the study. Women were classified as inadequate AR responders if they met one of the following criteria: (a) sustained at least one new vertebral or nonvertebral fragility fracture despite prior prescription of an antiresorptive therapy for at least 12 months; (b) had a lumbar spine, total hip or femoral neck BMD T-score -3.0 or less after documented prior antiresorptive treatment for at least 24 months; and/or (c) experienced a decrease of $\geq 3.5 \%$ in BMD at any one of the skeletal sites despite documented prescription of an antiresorptive agent in the preceding 24 months. All other women who had previously received antiresorptive treatment and who did not meet any of these criteria were assigned to the AR pretreated subgroup. For patients who had previously experienced an inadequate response to prior antiresorptive treatment, it was considered potentially unethical to randomize them to no active treatment or raloxifene; thus, these patients were given the option to be enrolled into substudy 2 , where they continued on teriparatide $(20 \mu \mathrm{g} /$ day) for the second year without randomization. It should be noted that the patients were not randomly distributed in the three study subgroups, but that they were assigned to the respective subgroups as observational cohorts.

\section{Biochemical markers of bone formation}

Serum concentrations of three biochemical markers of bone formation were measured at baseline and after 1 and 6 months of teriparatide treatment: (1) procollagen type I N-terminal propeptide (PINP); (2) bone-specific alkaline phosphatase (bALP); and (3) total alkaline phosphatase (t-ALP). Blood samples $(10 \mathrm{ml})$ were collected at any time between $7 \mathrm{am}$ and $4 \mathrm{pm}$, then serum samples were prepared and stored at $-20^{\circ} \mathrm{C}$ or lower at the study site for up to 4 months before being sent to a central laboratory (Clinical Sciences Centre, University of Sheffield) for storage at $-80^{\circ} \mathrm{C}$ and processing. All samples from an individual were assayed in a single analytical batch.

Serum PINP was measured by immunoassay on the Elecsys 2010 automated immunoanalyser (Roche Diagnostics $\mathrm{GmbH}$, Mannheim, Germany). The interassay (within day) analytical coefficient of variation (CV) was less than $1.1 \%$ over the reference interval. Serum b-ALP was measured by immunoassay using the Access Ostase Assay (Beckman Access, Beckman Coulter Inc., Fullerton, CA, USA). The interassay (within day) analytical CV was less than $4 \%$ over the reference interval. Cross reactivity of liver alkaline phosphatase in this assay is estimated to be about $10 \%$. tALP was measured using an enzyme kinetic assay using a dry-slide technique (Vitros 250, Ortho Clinical Diagnostics, Rochester, NY, USA). The interassay CV was $4.1 \%$.

To assess the reproducibility of biochemical assessment for the calculation of the signal-to-noise ratio in patients taking teriparatide, an additional serum sample was collected within 3-14 days after the 6-month visit in 83 women from the UK participant study sites. The 6-month visit rather than the baseline visit was chosen to avoid any systematic confounders due to the multiple therapeutic changes that occurred around the time of baseline (withdrawal of prior antiresorptive treatment, initiation of calcium supplementation). These 
additional samples were assayed within the same analytical batch as other samples from the same participant. The 6month visit was selected as the appropriate time point for this assessment because bone formation markers were expected to have reached their peak value by this time.

\section{Assessment of BMD}

Areal BMD at the lumbar spine (LS; L1-L4) and hip (total hip and femoral neck) was assessed by DXA (using Hologic, Lunar or Norland scanners) at baseline and at 6 , 12,18 and 24 months of teriparatide treatment [for details see: $21,27,28]$. Quality assessments and evaluations were performed by a central reader (Bioimaging Technologies, Leiden, The Netherlands).

\section{Statistical analysis}

The bone marker analysis of this nonrandomized cohort was based on a full analysis set and included all patients who took at least one dose of study medication and had at least one post-baseline bone marker determination $(\mathrm{n}=758)$. All non-missing data were included and no imputations for missing data were performed. In addition, a per protocol analysis was completed, which included 651 subjects who were $>80 \%$ compliant with the study medication in the first 6 months (when the bone markers were assessed) and had all three measurements of the bone markers available for analysis. For the Spearman correlations with BMD and the relationship with incident fractures, the analysis included those patients who received daily teriparatide treatment for up to 24 months ( $\mathrm{n}=468)$.

Baseline patient demographic characteristics of the three defined subgroups (treatment-naïve, AR-pretreated, and inadequate AR responders) were compared using ANOVA. The duration of previous medication was compared between the AR-pretreated and inadequate AR responder subgroups.

The biochemical bone markers have a log normal distribution; therefore, the data were transformed before analysis. Mixed model repeated measure (MMRM) was used to assess the within-patient change from baseline and the between-group differences in bone markers. Withinpatient changes at each visit were assumed to be correlated but no assumptions regarding the structure of these correlations were made. The MMRM assumes data are missing at random; all non-missing data contribute to the model. This model assumes that the bone markers of those patients with missing data would behave in a similar way to those of patients with non-missing data.

Change in BMD to 24 months was modeled using ANOVA. The amount of variance in the change in BMD to 24 months was modeled. A stepwise selection method of PINP concentration at baseline, and change in PINP to
1 month and 6 months was used to find the optimal model, which was defined by the largest proportion of variance explained (the highest $\mathrm{R}^{2}$ ).

The signal-to-noise ratio $(\mathrm{S} / \mathrm{N})$ was determined for each bone marker using the results of the 83 UK-based patients with duplicate measurements, where the "signal" was the absolute change of log-transformed values while on therapy, and the "noise" was the within-subject biological variability of the measurement (standard deviation of logtransformed measurements on therapy calculated from the duplicate differences on the subset). Data were analyzed by Eli Lilly and Company using SAS software, version 9.0 (SAS Institute, Inc., Cary, North Carolina, USA), and independently by the first author (AB).

\section{Results}

\section{Patient disposition}

Of the 868 patients enrolled in the study, two were excluded from all analyses because they had no postbaseline data. Of the 866 evaluable patients at baseline, 758 $(87.5 \%)$ had at least one evaluable post-baseline bone marker measurement and were included in the analysis: treatment-naïve $(n=181)$, AR pretreated $(n=209)$, and inadequate AR responders $(n=368)$ (Fig. 1). Of these 758 patients, 468 in the three subgroups together continued with a second year of teriparatide treatment, and 443 completed the second year of teriparatide treatment (Fig. 1).

\section{Baseline characteristics}

The baseline characteristics of the 758 patients by previous antiresorptive treatment subgroup are given in Table 1. The three subgroups did not differ in age, BMI, or BMD at the hip. Pairwise comparisons showed that LS BMD and height were significantly lower in the inadequate AR responder group than in the other two groups (Table 1). We also observed some variability in weight, height and years since menopause among the subgroups, but these differences are probably a consequence of the non-randomized way the patients were assigned to the subgroups.

Table 2 summarizes the type and duration of previous antiresorptive medications. Among the AR pretreated group, $83.7 \%$ used a bisphosphonate for a median of 7 months, whereas $91.8 \%$ of inadequate AR responders had used a bisphosphonate for a median of 36 months. The median lag time between stopping the last antiresorptive treatment and starting teriparatide was 28 days (interquartile range: $18-115$ days) for the AR pretreated subgroup, and 29 days (interquartile range: $17-56$ days) for the inadequate AR responder subgroup. 


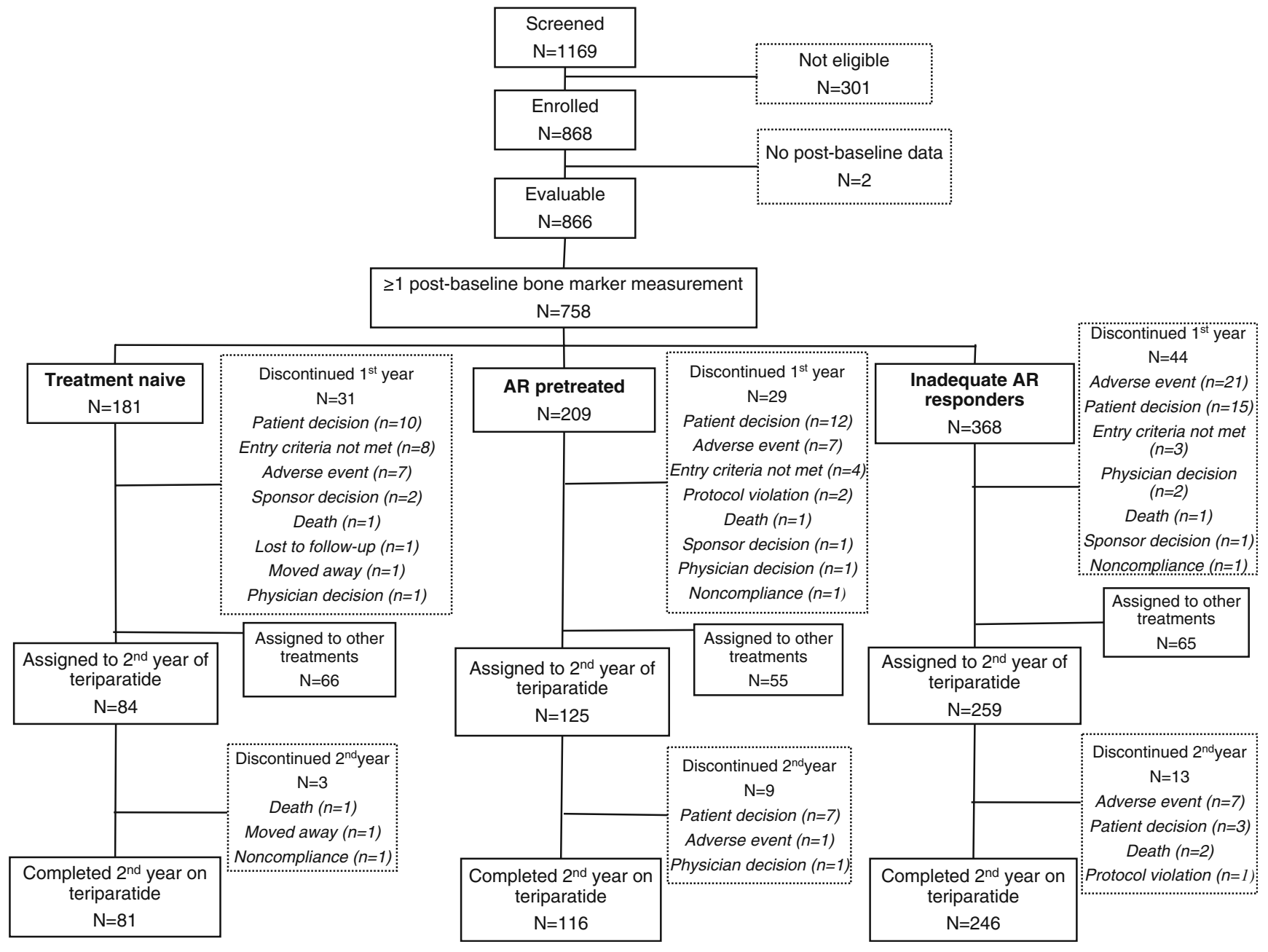

Fig. 1 Patient disposition

Bone formation markers response to teriparatide

Table 3 shows the bone marker values at baseline, 1 month and 6 months in the three subgroups. Pairwise comparisons showed that both the AR pretreated and inadequate AR responder groups had significantly lower baseline values of bone markers than the treatment-naïve group. In response to teriparatide treatment, serum levels of PINP, b-ALP and tALP increased significantly in all subgroups at 1 and 6 months. MMRM analysis showed that the concentrations of bone markers differed among the subgroups (Table 3). Thus, at 1 month, there were no significant differences between AR pretreated and inadequate AR responders for any of the bone markers, but these two subgroups had PINP values approximately $30 \%$ lower and b-ALP values approximately $15 \%$ lower than the treatment-naïve patients. However, by 6 months, there were no significant differences between the treatment-naïve and previously treated subgroups for any of the bone formation markers (Table 3). Figure 2 shows the percentage change from baseline for each of the three bone markers in the three subgroups. Because of baseline differences in bone marker levels due to prior AR treatment, calculation as percentage change provides a different impression of the data. This should be taken into account when interpreting such data.

The analysis of the bone marker results in the per protocol population $(n=651)$ yielded similar results to the full analysis cohort.

\section{$\mathrm{BMD}$ response to teriparatide}

The mean percent increase in lumbar spine BMD from baseline to 24 months in the analyzed cohort was, on average, $10.3 \%$ for the total group of teriparatide-treated patients. The absolute change (mean $\pm \mathrm{SD}$ ) in lumbar spine BMD from baseline was $0.097 \pm 0.052 \mathrm{~g} / \mathrm{cm}^{2}(13.1 \%)$ in the treatment-naïve subgroup $(\mathrm{n}=80), 0.077 \pm 0.048 \mathrm{~g} / \mathrm{cm}^{2}$ $(10.7 \%)$ in the AR pretreated subjects $(n=115)$, and 0.068 $\pm 0.049 \mathrm{~g} / \mathrm{cm}^{2}(9.4 \%)$ in the inadequate $\mathrm{AR}$ responder group $(n=245)$. 
Table 1 Baseline characteristics of the total study population and of each subgroup by previous treatment*

\begin{tabular}{lllll}
\hline & \multicolumn{2}{l}{ Previous treatment subgroup } & & \\
\cline { 2 - 5 } Characteristic & Treatment- naïve & AR pretreated & Inadequate AR responder & Total \\
\hline N (\%) & $181(23.9)$ & $209(27.6)$ & $368(48.5)$ & $758(100.0)$ \\
Age (years) & $70.4(7.7)$ & $69.3(7.2)$ & $69.8(7.5)$ & $69.8(7.5)$ \\
Time since menopause (years) & $22.7(9.5)$ & $21.4(9.0)^{\mathrm{d}}$ & $23.4(9.9)$ & $22.7(9.6)$ \\
Weight $(\mathrm{kg})$ & $64.4(11.6)^{\mathrm{a}}$ & $62.8(10.9)$ & $61.3(10.9)$ & $62.5(11.1)$ \\
Height $(\mathrm{cm})$ & $158.3(7.0)^{\mathrm{a}}$ & $157.8(7.1)^{\mathrm{a}}$ & $155.7(7.4)$ & $156.9(7.3)$ \\
BMI $\left(\mathrm{kg} / \mathrm{m}^{2}\right)$ & $25.7(4.4)$ & $25.3(4.4)$ & $25.2(4.0)$ & $25.4(4.2)$ \\
Lumbar spine BMD $\left(\mathrm{g} / \mathrm{cm}^{2}\right)$ & $0.751(0.114)^{\mathrm{b}}$ & $0.746(0.120)$ & $0.728(0.117)$ & $0.738(0.118)$ \\
Lumbar spine BMD $\left(\mathrm{T}-\mathrm{Score}^{\mathrm{b}}\right)$ & $-3.01(0.96)^{\mathrm{c}}$ & $-3.16(0.91)^{\mathrm{d}}$ & $-3.35(0.95)$ & $-3.21(0.95)$ \\
Total hip BMD $\left(\mathrm{g} / \mathrm{cm}^{2}\right)$ & $0.703(0.105)$ & $0.703(0.111)$ & $0.687(0.110)$ & $0.695(0.110)$ \\
Femoral neck BMD $\left(\mathrm{g} / \mathrm{cm}^{2}\right)$ & $0.622(0.108)$ & $0.632(0.116)$ & $0.620(0.116)$ & $0.624(0.114)$ \\
\hline
\end{tabular}

*for definition of patient subgroups, see the "Participants" sub-heading in the Methods section.

Data are presented as mean (standard deviation) with ANOVA test. Only patients with non missing biochemical markers at baseline are included $\mathrm{BMI}=$ body mass index

$\mathrm{BMD}=$ bone mineral density

${ }^{\mathrm{a}} \mathrm{p}<0.005$ vs Inadequate responders; ${ }^{b} \mathrm{p}<0.05$ vs Inadequate responders; ${ }^{c} \mathrm{p}=0.0001$ vs Inadequate responders; ${ }^{\mathrm{d}} \mathrm{p}<0.05$ vs Inadequate responders

At 24 months, femoral neck BMD was increased from baseline in all three subgroups of patients: $0.029 \pm 0.036 \mathrm{~g} / \mathrm{cm}^{2}$ (4.7\%), $0.020 \pm 0.041 \mathrm{~g} / \mathrm{cm}^{2}(3.2 \%)$, and $0.023 \pm 0.040 \mathrm{~g} / \mathrm{cm}^{2}$ $(3.7 \%)$ for the treatment naïve $(n=76)$, AR pretreated $(n=112)$ and inadequate AR responders $(\mathrm{n}=239)$, respectively. Similar results were observed for the total hip BMD (data not shown). These BMD findings were similar to those previously reported for the total cohort of 503 patients [21].

Signal-to-noise ratios

The signal-to-noise ratios for PINP, b-ALP and t-ALP were $12.4,8.0$ and 4.2 , respectively. The intraclass correlation coefficients of bone markers measured at two time points
(3-14 days apart) were $0.983,0.988$ and 0.972 for PINP, bALP and t-ALP, respectively.

Correlations between PINP and BMD response

Table 4 presents the Spearman correlation coefficients between absolute levels of PINP and their changes at 1 and 6 months, and the change in BMD at 24 months of teriparatide therapy. Bone turnover status at baseline correlated significantly with subsequent BMD responses at 24 months. The highest coefficient value was for the correlation between PINP concentration at 1 month and the change in LS BMD to 24 months $(\mathrm{r}=0.365 ; \mathrm{p}<0.0001)$ (Table 4). This coefficient was slightly higher in the
Table 2 Type and duration of previous antiresorptive (AR) medication in the AR pretreated and inadequate $\mathrm{AR}$ responder subgroups

$\mathrm{ET} / \mathrm{EPT}=$ estrogen therapy/estrogen progestin therapy; SERM $=$ selective estrogen receptor modulator

$\mathrm{IV}=$ intravenous

\begin{tabular}{llllll}
\hline Prior AR Therapy & \multicolumn{2}{l}{ AR pretreated $(\mathrm{n}=209)$} & & \multicolumn{2}{l}{ Inadequate AR responder $(\mathrm{n}=368)$} \\
\cline { 2 - 3 } & $\mathrm{N}(\%)$ & $\begin{array}{c}\text { Duration, months } \\
\text { median }(\mathrm{Q} 1, \mathrm{Q} 3)\end{array}$ & & $\mathrm{N}(\%)$ & $\begin{array}{l}\text { Duration, months } \\
\text { median }(\mathrm{Q} 1, \mathrm{Q} 3)\end{array}$ \\
\hline Any Antiresorptive & $209(100.0)$ & $10(2,18)$ & & $368(100.0)$ & $54(32,89)$ \\
Any Bisphosphonate & $175(83.7)$ & $7(2,15)$ & & $338(91.8)$ & $36(24,59)$ \\
Alendronate & $120(57.4)$ & $7(1,13)$ & & $218(59.2)$ & $26(13,49)$ \\
Risedronate & $55(26.3)$ & $3(1,11)$ & & $110(29.9)$ & $19(9,26)$ \\
Etidronate & $25(12.0)$ & $9(1,17)$ & & $145(39.4)$ & $35(19,45)$ \\
IV Bisphosphonates & $12(5.7)$ & $9(6,17)$ & & $40(10.9)$ & $17(11,36)$ \\
SERM & $26(12.4)$ & $7(2,13)$ & & $65(17.7)$ & $21(13,30)$ \\
All ET/EPT & $24(11.5)$ & $28(12,48)$ & & $98(26.6)$ & $82(38,130)$ \\
Calcitonin & $24(11.5)$ & $3(1,8)$ & $65(17.7)$ & $13(4,36)$ \\
Vitamin D Metabolites & $2(1.0)$ & $8(4,12)$ & & $14(3.8)$ & $34(13,55)$ \\
\hline
\end{tabular}


Table 3 Mean bone marker values ${ }^{\mathrm{a}}$ (95\% confidence intervals) at baseline, 1 month and 6 months in the treatment naïve, AR pretreated and inadequate $\mathrm{AR}$ responder subgroups

\begin{tabular}{|c|c|c|c|c|c|c|}
\hline & \multirow[t]{2}{*}{ Treatment naive } & \multirow[t]{2}{*}{ AR pretreated } & \multirow[t]{2}{*}{ Inadequate $\mathrm{AR}$ responder } & \multicolumn{3}{|l|}{ p-value ${ }^{b}$} \\
\hline & & & & $\begin{array}{l}\text { AR pretreated } \\
\text { vs. naive }\end{array}$ & $\begin{array}{l}\text { Inadequate } \\
\text { AR responder } \\
\text { vs. naive }\end{array}$ & $\begin{array}{l}\text { AR pretreated } \\
\text { vs. inadequate } \\
\text { AR responder }\end{array}$ \\
\hline \multicolumn{7}{|c|}{ PINP $(\mu \mathrm{g} / \mathrm{L})$} \\
\hline Baseline & $48.2(43.8-53.1)$ & $26.1(23.8-28.5)$ & $27.5(25.7-29.4)$ & $<0.0001$ & $<0.0001$ & 0.363 \\
\hline 1 month & $85.5(78.0-93.6)$ & $56.6(52.0-61.6)$ & $62.2(58.4-66.3)$ & $<0.0001$ & $<0.0001$ & 0.079 \\
\hline 6 months & $129.1(116.1-143.5)$ & $118.2(106.9-130.6)$ & $136.6(126.8-147.2)$ & 0.235 & 0.387 & 0.022 \\
\hline \multicolumn{7}{|c|}{ b-ALP $(\mu \mathrm{g} / \mathrm{L})$} \\
\hline Baseline & $12.9(12.1-13.7)$ & $10.1(9.6-10.7)$ & $10.2(9.8-10.7)$ & $<0.0001$ & $<0.0001$ & 0.775 \\
\hline 1 month & $14.3(13.5-15.2)$ & $12.0(11.4-12.7)$ & $12.4(11.9-12.9)$ & $<0.0001$ & $<0.0001$ & 0.374 \\
\hline 6 months & $18.9(17.6-20.3)$ & $17.6(16.5-18.8)$ & $19.2(18.3-20.2)$ & 0.152 & 0.749 & 0.045 \\
\hline \multicolumn{7}{|c|}{$\mathrm{t}-\mathrm{ALP}(\mu \mathrm{g} / \mathrm{L})$} \\
\hline Baseline & $69.6(66.5-72.9)$ & $64.1(61.4-66.9)$ & $63.3(61.3-65.4)$ & 0.010 & 0.001 & 0.655 \\
\hline 1 month & $72.5(69.4-75.7)$ & $67.9(65.2-70.8)$ & $68.0(65.9-70.1)$ & 0.034 & 0.019 & 0.976 \\
\hline 6 months & $82.9(79.0-87.0)$ & $82.1(78.5-85.9)$ & $84.1(81.3-87.0)$ & 0.777 & 0.630 & 0.407 \\
\hline
\end{tabular}

${ }^{a}$ Adjusted by baseline P1NP concentration and BMD values, and duration of prior AR treatment

${ }^{\mathrm{b}}$ MMRM of log-transformed data

$\mathrm{AR}=$ antiresorptive; $\mathrm{PINP}=$ procollagen Type $1 \mathrm{~N}$-terminal propeptide; $\mathrm{b}$-ALP $=$ bone-specific alkaline phosphatase; $\mathrm{t}$-ALP $=$ total alkaline phosphatase

subgroup of osteoporosis treatment-naïve patients $(\mathrm{r}=$ $0.405 ; \mathrm{p}<0.0001$ ) (data not shown). The coefficient values were lower for the changes in total hip and femoral neck BMD (Table 4).

The best-fit model for predicting change from baseline in LS BMD for all patients contained prior duration of antiresorptive treatment, increases in PINP after 1 month, and PINP concentrations at 1 and 6 months, and accounted for $17.4 \%$ of the total variation in change in LS BMD to 24 months. In this model, prior duration of antiresorptive treatment was negatively associated with BMD changes at the LS, as previously described [21]. The different models explored for predicting change from baseline in total hip or femoral neck BMD to 24 months accounted for a maximum of $5.6 \%$ of the total variation in the best-fit model which included duration of prior antiresorptive treatment and PINP concentration at 1 month.

Forty-nine subjects experienced an incident fracture during follow-up. No relationship between baseline levels or changes in PINP concentrations after 1 and 6 months of treatment with teriparatide and the overall risk of clinical fractures was found $(\mathrm{p}>0.05)$.

\section{Discussion}

Our results showed that teriparatide $20 \mu \mathrm{g}$ /day was associated with significant early increases in biochemical markers of bone formation at 1 month, and that these changes were increased further after 6 months of therapy. The increases in bone markers occurred regardless of previous antiresorptive therapy, although the absolute values after 1 month of teriparatide treatment were lower in subjects who had received previous antiresorptive therapy than in treatment-naïve subjects. This delayed increase in bone formation markers in pretreated patients is likely associated with the bone turnover inhibition induced by long-term antiresorptive therapy as shown with the lower values of the bone markers at the baseline visit compared with treatmentnaïve individuals. However, as early as 6 months, teriparatide overcomes the inhibition of bone remodelling induced by prior antiresorptive therapy.

Previous studies investigated the changes in various biochemical markers of bone turnover during treatment with teriparatide or $\mathrm{PTH}(1-84)$ in osteoporosis treatmentnaïve subjects. They reported significant increases in bone formation markers as early as 1 month after starting teriparatide or $\mathrm{PTH}(1-84)$ therapy in postmenopausal women with osteoporosis [11, 13, 14, 29-31], in patients with glucocorticoid-induced osteoporosis [10, 32], and in men with idiopathic and hypogonadal osteoporosis receiving teriparatide $[17,33,34]$. The changes in PINP, b-ALP and t-ALP during the first 6 months of teriparatide treatment in the present study are consistent with those reported previously in treatment-naïve subjects. 
Fig. 2 Percentage change from baseline of the bone markers (a) PINP, (b) b-ALP, and (c) t-ALP after 1 and 6 months of teriparatide treatment in the treatment naïve, AR pretreated and inadequate $\mathrm{AR}$ responder subgroups
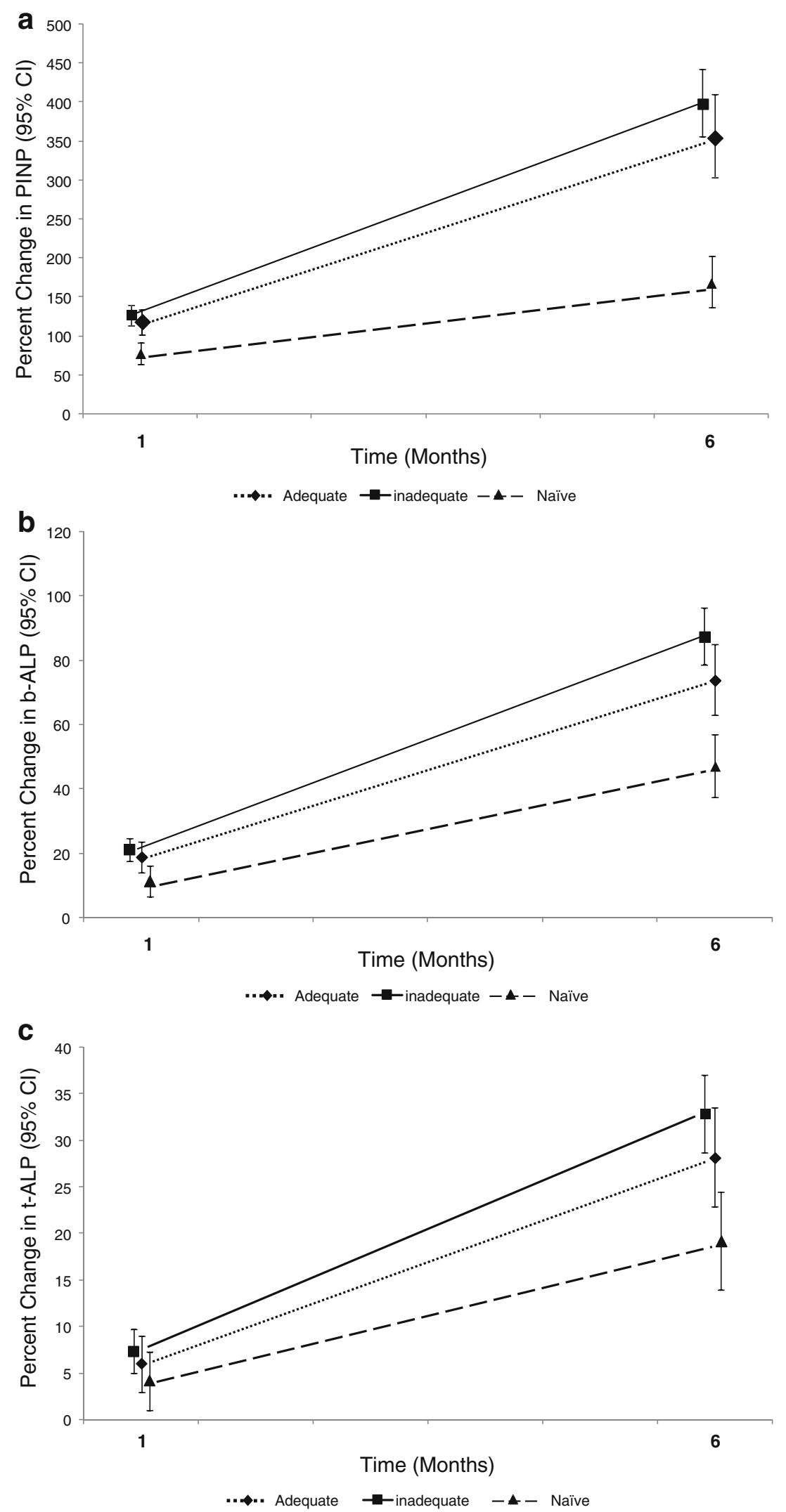
Table 4 Spearman correlation coefficients (p-values) between absolute levels of PINP or PINP changes at 1 and 6 months, and the change in BMD at

24 months of teriparatide therapy.

BMD, bone mineral density; PINP, procollagen Type $1 \mathrm{~N}$ terminal propeptide

n.s., not significant $(\mathrm{p}>0.05)$

\begin{tabular}{lllll}
\hline & Time point (month) & \multicolumn{2}{l}{ Change from baseline in BMD $(24$ months $)$} \\
\cline { 3 - 5 } & & Lumbar spine $(\mathrm{n}=414)$ & Total hip $(\mathrm{n}=401)$ & Femoral neck $(\mathrm{n}=401)$ \\
\hline PINP & Baseline & $0.301(<0.0001)$ & $0.218(<0.0001)$ & $0.116(<0.05)$ \\
& 1 & $0.365(<0.0001)$ & $0.141(<0.005)$ & $0.081($ n.s. $)$ \\
& 6 & $0.219(<0.0001)$ & $0.111(<0.05)$ & $0.107(<0.05)$ \\
\multirow{2}{*}{ PINP } & $\Delta 1$ & $0.213(<0.0001)$ & $0.000($ n.s. $)$ & 0.081 (n.s. $)$ \\
& $\Delta 6$ & $0.117(<0.05)$ & 0.035 (n.s) & 0.070 (n.s. $)$ \\
\hline
\end{tabular}

Several reports have shown that the increase in bone formation markers induced by teriparatide or $\mathrm{PTH}(1-84)$ is smaller or shows a delay in subjects who have been previously treated with a potent bisphosphonate $[16,17$, 19]. This effect is even more marked if the patients are receiving concomitant treatment with potent antiresorptives $[15,19]$. However, the delayed effect on bone formation markers observed during the first months of teriparatide or PTH(1-84) therapy is overcome with longer treatment duration, and the differences between treatment-naïve patients and prior antiresorptive drugs users are no longer statistically significant after 6 months of treatment. Our results are consistent with other studies that compared the effects of different types of antiresorptive drugs on the response of biochemical markers of bone turnover during teriparatide treatment. During the first 5 months of teriparatide therapy, postmenopausal women with osteoporosis previously treated with risedronate for a minimum of 24 months experienced a statistically significant greater increase in bone marker turnover than patients previously treated with alendronate, but the difference was no longer significant after 6 and 12 months of continuous treatment [35]. Our bone marker and BMD results confirm that longterm teriparatide treatment is able to reverse the low bone turnover status induced by treatment with potent bisphosphonates. This can also be observed at the tissue level with the described changes in microdamage accumulation and dynamic histomorphometric parameters in humans [36-38].

We analyzed the performance of three bone formation markers to monitor teriparatide treatment by evaluating the signal-to-noise ratio. In our large cohort of patients, most of whom had prior bisphosphonate treatment, PINP was the most responsive marker and showed the highest value, confirming previous findings in osteoporosis treatmentnaïve patients [39]. This finding has implications for monitoring patients treated with teriparatide and may also inform the design of studies of new anabolic agents for osteoporosis. The smaller changes in b-ALP and especially t-ALP indicate these biochemical markers are of much less value to monitor teriparatide treatment effects. This is not unexpected since the liver isoform of alkaline phosphatase makes up half of t-ALP and, hence, attenuates any change in the activity of the bone isoform.

In the present study, there were significant and positive correlations between the absolute values of PINP and the changes in BMD at both the lumbar spine and hip after 24months of teriparatide treatment. This was also found for the absolute increase from baseline in PINP and the 24month change in BMD at the lumbar spine, but not at the hip. As the positive correlation was observed at 1 month after starting teriparatide treatment, this bone marker may provide an early indication of responsiveness to teriparatide. However, the correlations were generally modest, and changes in PINP only explained $17.4 \%$ of the BMD changes at the lumbar spine and less than $6 \%$ at the hip in the best-fit models. Higher correlations between PINP and BMD changes after teriparatide treatment have been reported by Cosman et al. in patients pretreated with raloxifene $(\mathrm{r}=0.7)$ [40], and in subjects who received alendronate for a long period before starting therapy with parathyroid hormone [18].

The finding that the strongest association between changes in bone formation markers and BMD occurs at the spine is likely attributable to the faster rate of bone remodeling and greater response to teriparatide and $\mathrm{PTH}(1-$ 84 ) at trabecular sites, in comparison with the more modest association at the hip where more cortical bone is present.

The best correlation observed in our study (PINP concentration at 1 month and LS BMD change at 24 months; $\mathrm{r}=0.365, \mathrm{p}<0.001$ ) was higher than the correlation reported for a subset of osteoporosis treatmentnaïve postmenopausal women in the Fracture Prevention Trial. Chen et al. [13] reported that the Spearman correlation coefficient between the increase in PINP at 3 months and the increase in LS BMD at 18 months was $0.26(\mathrm{p}<0.05)$ in subjects receiving teriparatide $20 \mu \mathrm{g}$ daily. The same authors [13] reported a higher correlation $(\mathrm{r}=$ 0.63 ) for the increase in PICP at 1 month and LS BMD change. However, that correlation has to be interpreted with caution since it pertained to all pooled groups, including subjects treated with placebo and with two different doses of teriparatide, which magnified the variation of the 
measured change and, hence, increased the correlation coefficient. In another analysis with the full-length peptide PTH(1-84) in patients from the PaTH trial, Bauer et al. [29] showed that each standard deviation (SD) increase in 3month change in PINP was positively associated with a $4.0 \%$ increase in spine BMD and a $1.3 \%$ increase in hip BMD measured using DXA. These associations were even more striking when BMD changes were measured by quantitative computerized tomography (QCT): thus, each SD increase in the 3-month change in PINP was associated with a $21.2 \%$ increase in spine QCT trabecular BMD and a $7.0 \%$ increase in hip QCT trabecular BMD.

There are several limitations of this study. First, it was open-label and did not include a placebo or control group. However, biochemical markers of bone turnover and BMD are unlikely to be influenced by a lack of blinding. Moreover, the central laboratory personnel who performed the analyses were blind to the patients' treatment assignments and previous medication history. Second, because data on prior osteoporosis treatments were obtained retrospectively at baseline, we do not have accurate details on adherence and compliance to those treatments. Third, only bone formation markers and not bone resorption markers were measured; therefore, we do not get a full picture of bone turnover. Fourth, the number of fractures observed in this cohort was small. Thus, the lack of a significant relationship between changes in biochemical markers and fracture risk should be interpreted with caution. Further studies are needed to define the role of biochemical markers as predictors of fracture risk during teriparatide therapy. Finally, the subjects of this study were not randomized to the three analysis subgroups, which represent observational cohorts.

The strength of this study lies in its external validity. We included women with severe postmenopausal osteoporosis regardless of prior antiresorptive treatment and their response (or lack of response) to it. By keeping the inclusion and exclusion criteria broad, it was possible to recruit almost all women for whom teriparatide was indicated, thereby assembling a study cohort whose properties are similar to those of patients suitable for treatment with teriparatide in routine care. Of note, we only analyzed patients who had stopped their prior antiresorptive therapy before starting teriparatide; therefore, our results may differ from those studies where patients continued the antiresorptive concomitantly with teriparatide $[15,19]$.

In conclusion, teriparatide treatment is associated with a significant increase in biochemical markers of bone formation at 1 and 6 months. The bone formation marker response in patients does not seem to be adversely influenced by prior antiresorptive therapy, and can be detected at 1 month of therapy. After 6 months of treatment, bone formation markers are at a similar level regardless of prior osteoporosis treatment. Although indices of bone formation or change in formation were only modestly predictive of change in BMD at the spine or total hip at 24 months, and were not correlated with fracture outcomes, PINP appears to be the most sensitive bone marker to assess a therapeutic response to teriparatide.

Acknowledgements The authors thank Simon Cleall, MSc, for providing statistical advice; Deirdre Elmhirst, $\mathrm{PhD}$, Elmhirst Medical Writing Services, for assisting in the formatting and language of the manuscript, and the following individuals for providing technical assistance in conducting the study: Petra Ochs (study coordination), Ruth Alonso, David López, and Laura Briones (data management), and Alain Frix (study drug coordination). Dr Elmhirst's work on the manuscript was funded by the study sponsor. Steve Boonen is senior clinical investigator of the Fund for Scientific Research and is holder of the Leuven University Chair in Metabolic Bone Diseases. The authors thank the women who participated in this study; the doctors, study nurses, and support staff at the local sites; and the monitors and study managers in the participating countries. Funding was provided by Lilly Research Center, Europe

Conflicts of interest $\mathrm{AB}$ received funding from Eli Lilly to perform assays of bone turnover for this study. He has no other conflicts of interest and has received no personal funding from any pharmaceutical or diagnostic company. $\mathrm{KB}$ has served as consultant, received research grants from and has served on speakers' bureau for Eli Lilly. SB has received research funding and consulting fees from Eli Lilly. RE has previously consulted and received lecture fees from Eli Lilly and received grant support from 1998 to 2005 . FM, TN, CB, SL-L are employees of Eli Lilly. GS, JG have nothing to declare.

Open Access This article is distributed under the terms of the Creative Commons Attribution Noncommercial License which permits any noncommercial use, distribution, and reproduction in any medium, provided the original author(s) and source are credited.

\section{Appendix: EUROFORS principal investigators}

Austria: B. Obermayer-Pietsch, Lkh-Universitätsklinikum Graz; L. Erlacher, Krankenhaus der Elisabethinen, Klagenfurt; G. Finkenstedt, Landeskrankenhaus-Universitätskliniken, Innsbruck; Belgium: P. Geusens, Limburgs Universitair Centrum, Diepenbeek; F. Raeman, Jan Palfijn Ziekenhuis, Merksem; F. van den Bosch, Elisabethziekenhuis, Damme; Y. Boutson, Cliniques Universitaires de Mont Godinne, Yvoir; J.-M. Kaufman, Universitair Ziekenhuis Gent; S. Boonen, Universitair Ziekenhuis Gasthuisberg Leuven; Denmark: K. Brixen, University Hospital, Odense; B. Langdahl, Aarhus Amtssygehus; J.-E. B. Jensen, Hvidovre Hospital; Hvidovre; France: M. Audran, CHU d'Angers; C. Alexandre, Hôpital Bellevue, Saint Etienne; C. Roux, Hôpital Cochin, Paris; C.L. Benhamou, Hôpital Porte Madeleine, Orleans; C. Ribot, Hôpital Paule de Viguier, Toulouse; C. Cormier, Hôpital Cochin, Paris; J-L. Kuntz, Hôpital de Hautepierre, Strasbourg; A. Daragon, CHU de Bois Guillaume, Rouen; B. Cortet, 
Hôpital Roger Salengro, Lille; M. Laroche, Hôpital de Rangueil, Toulouse; M.C. de Vernejoul, Hôspital Lariboisiere, Paris; P. Fardellone, Hôpital Sud, Amiens; G. Weryha, Chu de Nancy Hôpital D'Adultes de Brabois, Vandoeuvre Les Nancy; Germany: H.W. Minne, Klinik - Der Fürstenhof, Bad Pyrmont; H-J. Heberling, Robert-Koch-Klinik, Leipzig; K. Badenhoop, Klinikum der Johann Wolfgang Goethe-Universität Frankfurt; H.G. Fritz, Berlin; J. Kekow, Krankenhaus Vogelsang, Vogelsang/Gommern; H. Moenig, Klinikum der Christian-AlbrechtsUniversitäts zu Kiel; T. Brabant, Krankenhaus St. Josef Stift Bremen; H-P. Kruse, Univeritäts-Krankenhaus Eppendorf, Hamburg; W. Spieler, Zefor, Zerbst; R. Möricke, Magdeburg; A. Wagenitz, Berlin; F. Flohr, Universitätsklinikum Freiburg; J. Semler, Immanuel Krankenhaus Rheuma Klinik Berlin Wannsee; P. Hadji, Klinikum der Phillips- Universität, Marburg; P. Kaps, Braunfels; T. Hennigs, Osteoporose Studiengesellschaft bR, Frankfurt; R.R. Fritzen, Med.Klinik für Endokrinologie des Universitätsklinikums Düsseldorf; J. Feldkamp, Städtische Kliniken, Bielefeld; G. Hein, Klinikum der Friedrich-Schiller-Universität, Jena; U. Haschke, Osnabrück; C. Kasperk, Universitätsklinkum Heidelberg; J.D. Ringe, Klinikum Leverkusen; H. Radspieler, Osteoporose-Diagnostik und Therapiezentrum München; N. Vollmann, München; E. Blind, Klinikum der Universität Würzburg; M. Runge, AerpahKlinik Esslingen-Kennenburg; F. Jakob, Orthopädische Klinik König-Ludwig-Haus, Würzburg; H-G. Dammann, Klinikische Forschung Hamburg; S. Scharla, Bad Reichenhall; Greece: G. Lyritis, K.A.T. Hospital Of Athens, Kifissia; A. Avramides, Ippokratio Hospital, Thessaloniki; Iceland: G. Sigurdsson, Landspitalinn Haskólasjúkrahús, Reykjavik; B. Gudbjörnsson, Fjordungssjukrahusid Akureyri; Portugal: M.E. Simões, Instituto Portugues De Reumatologia, Lisboa; J. MeloGomes, Servimed, Lisboa; J.C. Branco, Hospital Egas Moniz, Lisboa; A. Malcata, Hospitais da Universidade, Coimbra; Spain: C. Díaz-Lopez, J. Farrerons, Hospital Santa Creu i Sant Pau, Barcelona; J. González de la Vera , H.U. Virgen Macarena, Sevilla; J.A. Román, H.U. Dr. Pesset, Valencia; X. Sans, Ciutat Sanitaria Vall D’Hebron, Barcelona; A. Laffón Hospital de la Princesa, Madrid; E. Rejón, H.U. Nuestra Señora de Valme, Sevilla; J. del Pino, Hospital Clínico, Salamanca; J. de Toro, Hospital Juan Canalejo, A Coruña; J. Babio, Hospital de Cabueñes, Gijón; C. González, Hospital Gregorio Marañón, Madrid; United Kingdom: C. Cooper, University of Southampton; I. Fogelman, Kings' College, London; S. Doherty, D. Purdie, Hull and East Yorkshire Hospitals NHS Trust; D. Reid, Grampian University Hospitals NHS Trust; M. Stone, Cardiff and Vale NHS Trust; S. Orme, P. Belchetz, Leeds Teaching Hospital NHS Trust; R. Eastell, University of Sheffield; W. Fraser, University of Liverpool; D. Hosking, Nottingham City Hospital NHS Trust; T. O’Neill, Salford Hospital NHS Trust; J. Compston, J. Reeve,
Addenbrookes NHS Trust; K. Adams, Bolton Hospitals NHS Trust; H. Taggart, Belfast City Hospitals Trust; A. Bhalla, Royal National Hospital for Rheumatic Diseases NHS Trust; M. Brown, Nuffield Orthopaedic Centre NHS Trust; T. Palferman, East Somerset NHS Trust; A. Woolf, Royal Cornwall Hospitals NHS Trust; T. Wheatley, Brighton and Sussex University Hospitals NHS Trust; P. Thompson, Poole Hospital NHS Trust; R. Keen, Royal National Orthopaedic Hospital NHS Trust; P. Ryan, The Medway NHS Trust; P. Selby, Manchester University Hospitals NHS Trust.

\section{References}

1. Dempster DW, Cosman F, Kurland ES, Zhou H, Nieves J, Woelfert I, Shane E, Plavetic K, Muller R, Bilezikian J, Lindsay R (2001) Effects of daily treatment with parathyroid hormone on bone microarchitecture and turnover in patients with osteoporosis: a paired biopsy study. J Bone Miner Res 16:1846-1853

2. Jiang Y, Zhao JJ, Mitlak BH, Wang O, Genant HK, Eriksen EF (2003) Recombinant human parathyroid hormone (1-34) [Teriparatide] improves both cortical and cancellous bone structure. J Bone Miner Res 18:1932-1941

3. Ma YL, Zeng Q, Donley DW, Ste-Marie LG, Gallagher JC, Dalsky GP, Marcus R, Eriksen EF (2006) Teriparatide increases bone formation in modeling and remodeling osteons and enhances IGF-II immunoreactivity in postmenopausal women with osteoporosis. J Bone Miner Res 21:855-864

4. Lindsay R, Zhou H, Cosman F, Nieves J, Dempster DW, Hodsman AB (2007) Effects of a one-month treatment with PTH(1-34) on bone formation on cancellous, endocortical, and periosteal surfaces of the human ilium. J Bone Miner Res 22:495-502

5. Keaveny TM, Donley D, Hoffmann PF, Mitlak BH, Glass EV, San Martin JA (2007) Effects of teriparatide and alendronate on vertebral strength as assessed by finite element modeling of QCT scans in women with osteoporosis. J Bone Miner Res 21:149-157

6. Zanchetta JR, Bogado CE, Ferretti JL, Wang O, Wilson MG, Sato M, Gaich GA, Dalsky GP, Myers SL (2003) Effects of teriparatide [recombinant human parathyroid hormone (1-34)] on cortical bone in postmenopausal women with osteoporosis. J Bone Miner Res 18:539-543

7. Sato M, Westmore M, Ma YL, Schmidt A, Zeng QQ, Glass EV, Vahle J, Brommage R, Jerome CP, Turner CH (2004) Teriparatide [PTH(134)] strengthens the proximal femur of ovariectomized nonhuman primates despite increasing porosity. J Bone Miner Res 19:623-629

8. Uusi-Rasi K, Semanick LM, Zanchetta JR, Bogado CE, Eriksen EF, Sato M, Beck TJ (2005) Effects of teriparatide [rhPTH(1-34)] treatment on structural geometry of the proximal femur in elderly osteoporotic women. Bone 36:948-958

9. Neer RM, Arnaud CD, Zanchetta JR, Prince R, Gaich GA, Reginster JY, Hodsman AB, Eriksen EF, Ish-Shalom S, Genant HK, Wang O, Mitlak BH (2001) Effect of parathyroid hormone (1-34) on fractures and bone mineral density in postmenopausal women with osteoporosis. N Engl J Med 344:1434-1441

10. Saag KG, Shane E, Boonen S, Marin F, Donley DW, Taylor KA, Dalsky GP, Marcus R (2007) Teriparatide compared with alendronate for the treatment of glucocorticoid-induced osteoporosis. N Engl J Med 357:2028-2039

11. McClung MR, San Martin J, Miller PD, Civitelli R, Bandeira F, Omizo M, Donley DW, Dalsky GP, Eriksen EF (2005) Opposite bone remodeling effects of teriparatide and alendronate in increasing bone mass. Arch Intern Med 165:1762-1768 
12. Canalis E, Giustina A, Bilezikian JP (2007) Mechanisms of anabolic therapies for osteoporosis. N Engl J Med 357:905-916

13. Chen P, Satterwhite JH, Licata AA, Lewiecki EM, Sipos AA, Misurski DM, Wagman RB (2005) Early changes in biochemical markers of bone formation predict BMD response to teriparatide in postmenopausal women with osteoporosis. J Bone Miner Res 20:962-970

14. Dobnig H, Sipos A, Jiang Y, Fahrleitner-Pammer A, Ste-Marie L-G, Gallagher JC, Pavo I, Wang J, Eriksen EF (2005) Early changes in biochemical markers of bone formation correlate with improvements in bone structure during teriparatide therapy. J Clin Endocrinol Metab 90:3970-3977

15. Black DM, Greenspan SL, Ensrud KE, Palermo L, McGowan JA, Lang TF, Garnero P, Bouxsein ML, Bilezkian JP, Rosen CJ, for the PaTH Study Investigators (2003) The effects of parathyroid hormone and alendronate alone or in combination in postmenopausal osteoporosis. N Engl J Med 349:1207-1215

16. Ettinger B, San Martin J, Crans G, Pavo I (2004) Differential effects of teriparatide on BMD after treatment with raloxifene or alendronate. J Bone Miner Res 19:745-751

17. Finkelstein JS, Leder BZ, Burnett SA, Wyland JJ, Lee H, de la Paz V, Gibson K, Neer RM (2006) Effects of teriparatide, alendronate, or both on bone turnover in osteoporotic men. J Clin Endocrinol Metab 91:2882-2887

18. Cosman F, Nieves J, Zion M, Woelfert L, Luckey M, Lindsay R (2005) Daily and cyclic parathyroid hormone in women receiving alendronate. N Engl J Med 353:566-575

19. Cosman F, Wermers RA, Recknor C, Mauck KF, Xie L, Glass EV, Krege JH (2009) Effects of teriparatide in postmenopausal women with osteoporosis on prior alendronate or raloxifene: differences between stopping and continuing the antiresorptive agent. J Clin Endocrinol Metab 94:3772-3780

20. Seibel MJ (2005) Biochemical markers of bone turnover. Part 1: biochemistry and variability. Clin Biochem Rev 26:97-122

21. Obermayer-Pietsch BM, Marin F, McCloskey EV, Hadji P, Farrerons J, Boonen S, Audran M, Barker C, Anastasilakis AD, Fraser WD, Nickelsen T, EUROFORS Investigators (2008) Effects of two years of daily teriparatide treatment on bone mineral density in postmenopausal women with severe osteoporosis with and without prior antiresorptive treatment. J Bone Miner Res 23:1591-1600

22. Eastell R, Nickelsen T, Marin F, Barker C, Hadji P, Farrerons J, Audran M, Boonen S, Brixen K, Melo-Gomes J, Obermayer-Pietsch BM, Avramidis A, Sigurdsson G, Glüer C-C (2009) Sequential treatment of severe postmenopausal osteoporosis following teriparatide: final results of the randomized, controlled European Study of Forsteo (EUROFORS). J Bone Miner Res 24:726-736

23. Graeff C, Chevalier Y, Charlebois M, Varga P, Pahr D, Nickelsen TN, Morlock MM, Glueer CC, Zysset PK (2009) Improvements in vertebral body strength under teriparatide treatment assessed in vivo by finite element analysis: results from the EUROFORS Study. J Bone Miner Res 24:1672-1680

24. Borggrefe J, Graeff C, Nickelsen TN, Marin F, Glüer CC (2010) Quantitative computed tomography assessment of the effects of 24 months of teriparatide treatment on 3-D femoral neck bone distribution, geometry and bone strength: results from the EUROFORS study. J Bone Miner Res 25:472-481. doi:10.1359/ JBMR.090820

25. Genant HK, Grampp S, Glüer CC, Faulkner KG, Jergas M, Hagiwara S, van Kuijk C (1994) Universal standardisation for dual $\mathrm{x}$-ray absorptiometry: patient and phantom cross-calibration results. J Bone Miner Res 9:1503-1514

26. Hanson J (1997) Standardization of femur bone mineral density. J Bone Miner Res 12:1316-1317

27. Graeff C, Timm W, Nickelsen TN, Farrerons J, Marin F, Barker C, Glüer C-C, for the EUROFORS High Resolution Quantitative
Computed Tomography Substudy Group (2007) Monitoring teriparatide associated changes in vertebral microstructure by high-resolution computed tomography in vivo: results from the EUROFORS study. J Bone Miner Res 22:1426-1433

28. Boonen S, Marin F, Obermayer-Pietsch B, Simoes ME, Barker C, Glass EV, Hadji P, Lyritis G, Oertel H, Nickelsen T, McCloskey EV, EUROFORS Investigators (2008) Effects of previous antiresorptive therapy on the bone mineral density response to two years of teriparatide treatment in postmenopausal women with osteoporosis. J Clin Endocrinol Metab 93:852-860

29. Bauer DC, Garnero P, Bilezikian JP, Greenspon SL, Ensrud KE, Rosen CJ, Palermo L, Black DM, for the PTH and Alendronate $(\mathrm{PaTH})$ Research Group (2006) Short-term changes in bone turnover markers and bone mineral density response to parathyroid hormone in postmenopausal women with osteoporosis. J Clin Endocrinol Metab 91:1370-1375

30. Black DM, Bilezikian JP, Ensrud KE, Greenspan SL, Palermo L, Hue T, Lang TF, McGowan JA, Rosen CJ, for the PaTH Study Investigators (2005) One year of alendronate after one year of parathyroid hormone (1-84) for osteoporosis. N Engl J Med 353:555-565

31. Greenspan SL, Bone HG, Ettinger MP, Hanley DA, Lindsay R, Zanchetta JR, Blosch CM, Mathisen AL, Morris SA, Marriott TB, for the Treatment of Osteoporosis with Parathyroid Hormone Study Group (2007) Effect of recombinant human parathyroid hormone (184 ) on vertebral fracture and bone mineral density in postmenopausal women with osteoporosis. Ann Intern Med 146:326-339

32. Lane NE, Sanchez S, Genant HK, Jenkins DK, Arnaud CD (2000) Short-term increases in bone turnover markers predict parathyroid hormone-induce spinal bone mineral density gains in postmenopausal women with glucocorticoid-induced osteoporosis. Osteoporos Int 11:434-442

33. Orwoll ES, Scheele WH, Paul S, Adami S, Syversen U, DiezPerez A, Kaufman JM, Clancy AD, Gaich GA (2003) The effect of teriparatide [human parathyroid hormone (1-34)] therapy on bone density in men with osteoporosis. J Bone Miner Res 18:9-17

34. Finkelstein JS, Hayes A, Hunzelman JL, Wyland JJ, Lee H, Neer RM (2003) The effects of parathyroid hormone, alendronate, or both in men with osteoporosis. N Engl J Med 349:1216-1226

35. Miller PD, Delmas PD, Lindsay R, Watts NB, Luckey M, Adachi J, Saag K, Greenspan SL, Seeman E, Boonen S, Meeves S, Lang TF, Bilezikian JP (2008) Early responsiveness of women with osteoporosis to teriparatide after therapy with alendronate or risedronate. J Clin Endocrinol Metab 93:3785-3793

36. Dobnig H, Stepan JJ, Burr DB, Li J, Michalska D, Sipos A, Petto H, Fahrleitner-Pammer A, Pavo I (2009) Teriparatide reduces bone microdamage accumulation in postmenopausal women previously treated with alendronate. J Bone Miner Res 24:19982006

37. Stepan JJ, Burr DB, Li J, Ma YL, Petto H, Sipos A, Dobnig H, Fahrleitner-Pammer A, Michalska D, Pavo I (2010) Histomorphometric changes by teriparatide in alendronate-pretreated women with osteoporosis. Osteoporos Int. doi:10.1007/s00198-009-1168-7

38. Lindsay R, Cosman F, Zhou H, Nieves JW, Bostrom M, Barbuto N, Dempster DW (2007) Prior alendronate treatment does not inhibit the early stimulation of osteoblast activity in response to teriparatide. J Bone Miner Res 22(Suppl):S124, Abstract

39. Eastell R, Krege JH, Chen P, Glass EV, Reginster JY (2006) Development of an algorithm for using PINP to monitor treatment of patients with teriparatide. Curr Med Res Opin 22:61-66

40. Cosman F, Nieves JW, Zion M, Barbuto N, Lindsay R (2008) Effect of prior and ongoing raloxifene therapy on response to PTH and maintenance of BMD after PTH therapy. Osteoporos Int 19:529-535 